\title{
Charting the competency-based eportfolio implementation journey
}

\author{
Barbara Anne Nicolls ${ }^{1}$, Maria Cassar ${ }^{2}$, Corinne Scicluna ${ }^{2}$, Sharon Martinelli ${ }^{2}$ \\ ${ }^{1}$ Directorate for Student Success, Buckinghamshire New University, UK, ${ }^{2}$ Department of \\ Nursing, University of Malta.
}

\begin{abstract}
As health professionals, nurses are responsible not only for staying abreast of current professional knowledge to provide effective care but also for managing their own career, professional growth and development. Nurse educators have acknowledged that eportfolios provide a means through which nurses can record and provide evidence of skills, achievements, experience, professional development and on-going learning, not only for themselves, but for the information and scrutiny of registration boards, employers, managers and peers. Recognising that practices to support these activities that foster 21st century learning should ideally start during their student years, the authors explored eportfolios as a valuable learning device for on-going personal and professional development for fostering students' lifelong learning and enhancing continuous personal and professional development. This paper describes the critical success factors for successful implementation of the Google Sites Practice eportfolio embedded in the three-year BSc(Hons) Nursing Programme in Malta. Evidence-based practice of successful eportfolio implementors was examined and their methods adapted to ensure the initiative had a sound foundation and fit for purpose. The authors argue that to be successful, eportfolio implementation must primarily be strategic, holistic, supported and have senior management buy-in and secondarily, have a robust tool, good pedagogy, and skilled and enthusiastic staff.
\end{abstract}

Keywords: Nursing; competency; implementation; eportfolio; Malta; nurse education. 


\section{Introduction}

Eportfolios are "digital presentations of a student's experiences, achievements and aspirations for a particular audience - the digital equivalent of a paper portfolio" (Joint Information Systems Committee, JISC 2019). In 2019, the Department of Nursing in the Faculty of Health Sciences at the University of Malta (UM) embarked on a two-phase project whereby the department developed and implemented a web-based Google Sites Practice eportfolio (GSPeP) in order to improve clinical competency assessment in the three-year Undergraduate Pre-registration Nursing Programme (UGNP).

GSPeP aims to support practice placement learning and is, therefore, embedded in the practice modules at each level in the nursing programme; it provides a cumulative evidence of practice placement learning and development. Hence, the GSPeP is an online representation of the student nurses' (SN) academic and professional accomplishments and achievements and enables the storage of their experiences and accomplishments in one place to highlight their nursing competencies. Essentially, competence is the capacity to carry out safe and effective practice on a developed basis of knowledge, skills, behaviours and attitudes. Attainment of competence is necessary in order to successfully complete the UGNP and be registered as a qualified nurse with the Council for Nurses and Midwives of Malta. The GSPeP is the SNs' evidence of working towards the required level of competence to enter a Professional Register of Nurses across the European Union.

It is clear that factors such as a robust tool, effective pedagogy and skilled and enthusiastic staff are all important, but, the authors believe success hinges on four critical factors: strategic, holistic, supported and senior management buy in. This paper aims to identify and act on the lessons learnt from implementing the GSPeP in Phase I in 2019-20 from the perspective of the project management team for a smoother delivery of Phase II.in 2020-21.

\section{Overview}

An average of 100 students register annually on the three-year BSc(Hons) UGNP programme which comprises an equal balance of theory and practice components. Attrition rate across the programme is consistently less than $8 \%$. The theoretical component is designed and delivered by a group of Nurse Educators (NEd) while the practice component is steered by practising qualified nurses across the national Health and Social sector. Individual roles and responsibilities are discussed below.

\subsection{Rationale for implementing GSPeP}

Electronic portfolios (eportfolios) appear to have numerous advantages over paper based portfolios: they support a greater variety of artefacts and allow for increased learner expression; are dynamic and multimedia driven; accessible by a large audience; contain meta- 
documentation; easy to store; and may serve to promote students academically and professionally (Buzzetto-More, 2006). Hence, in early 2019, following an evaluation of the then existing paper-based practice portfolio, the Department of Nursing joined other academic leaders (Jafari, 2004) in embracing the eportfolio for its fundamental benefits: sustainability, portability, versatility, feedback, transferability, shareability, to name a few. The curriculum team agreed that in line with the 21 st century developments, it was imperative for their SNs not only to be clinically competent but also to be digitally literate and therefore, a shift towards an eportfolio would lend itself well towards the development of both expected realms of performance amongst students.

The eportfolio initiative aims to provide SNs with an online space (GSPeP) to curate evidence pertaining to their learning which is accessible $24 / 7$ by all end users. It acts as both a guide and structure for the mapping of the SNs professional and personal journey. The eportfolio therefore, lends itself well towards the mission of Quality Assurance (QA) activities: internal and external quality audits required by the relevant QA authorities and the Council for Nurses and Midwives, the national professional regulatory body. Moreover, the eportfolio is an apt learning tool in itself because it helps students become reflective practitioners with a drive for lifelong learning complemented by a critical approach to self- assessment and selfimprovement.

In summary, the GSPeP serves the following purposes of eportfolios in educational settings as identified by Barrett (2001):

- learning ePortfolio: focuses on personal development through the use of selfevaluation and reflection and are formative in nature

- assessment ePortfolio: requires students to show through dialogic reflection on selected experiences how skills and knowledge development have been demonstrated

- $\quad$ presentation ePortfolio: showcases skills and attributes in the professional context

\subsection{Drivers for GSPeP}

The GSPeP was set up in response to the growing demand for the submission of digital portfolios by applicants responding to calls for recruitment and career promotion opportunities from stakeholders the UM's wider strategy - further inclusion of technology in all its operations towards more sustainable processes and the GSPeP is a novel initiative which extends the current adoption of the MOODLE digital platform for the programme delivery. 


\section{The GSPeP implementation process}

The implementation of GSPeP which followed the guide provided by the Joint Information Systems Committee (JISC, 2012) will be presented in this section.

\subsection{Vision and Scoping}

To avoid misunderstanding and ineffective implementation of the GSPeP due to the diverse uses of eportfolios, the vision was made clear in an easily communicable way to all the stakeholders at the conception of the idea.

"By implementing the GSPeP, the Department of Nursing, UM will empower students to become active participants in their own personalised education. Through use of reflection, technology and collaboration, SNs, link lecturers and mentors will develop knowledge, skills and attitudes that will lead them to achieve their lifelong goals".

The scope was that by the end of December 2020, the BSc(Hons) Nursing and the Higher Diploma in Nursing (2019 cohorts) would own and manage the GSPeP for the purpose of demonstrating achievement of the professional competencies. A clear timetable (Table 1) with milestones helped the Project Team to keep on track with the project schedule. 
Table 1. GSPeP implementation schedule.

\section{Phase I: Planning and Implementation}

Prepare Training digital packages: ep101, 102,103,104, 105,106, 107 video and pdf, Survival guide - ebook

$06.01 .2020-$

UoM eportfolio (prototype) UM FoE shared, zipped Google drive:

survival guide (staff) Google drive: survival guide

31.01 .2020

06.01.2020 -

31.01 .2020

Staff Training

$28 / 01 / 2020$

Organise Orientation (Higher Diploma \& BSc(Hons) Nursing

$03 / 02 / 2020 \&$

students) via ZOOM video conferencing: Google Sites eportfolio

development process Step I: Google drive as storage for evidence

$04 / 02 / 2020$

(2hours/group)

Staff training - Create Google Sites eportfolio, populate with

evidence, publish and share + eportfolio project team meeting

$12 / 02 / 2020 \&$

$18 / 02 / 2020$

Prepare training packs eP106,107, 108, 109, 110- Google Sites

March 2020

compile all training materials in eBook

Q\& A session with staff (via google forms).

April 2020

Interim eportfolio development survey with students

April/May 2020

Interim eportfolio development survey with LL

May 2020

Zoom catch up with students : slides

May 2020

Review student progress via shared Google Drive.

May 2020

Year 1 students to submit formative reflections on an episode

10.06 .2020

of online learning by 10 June 2020

Review student reflections with LL and identify areas for improvement in reflective writing

Early June 2020

Collate findings from Initial students survey in preparation for

June 2020

LL meeting on 8 July

Collate findings from Interim students survey in preparation

June 2020

for LL meeting on 8 July

Collate findings from LLs survey in preparation for LL meeting on 8

June 2020 July

Zoom meeting with LL - wrap up

June 2020

Zoom meetings with students - reflective writing (3 groups)

9 July AM 9 July PM

10 July AM

Evaluation of project

September 2020

Write up and submit report

October 2020 


\subsection{Planning and Design}

A critical success factor for GSPeP implementation is to have clear roles and responsibilities. JISC (2012) eportfolio implementation study found that the Implementation Manager role was critical for effective implementation. A UK-based eportfolio champion was headhunted through eportfolio research publications to lead the planning, executing, monitoring, controlling and evaluating the GSPeP initiative. The project manager (PM) delivered the project on time, within the budget and brief while keeping everyone in the know and happy. Additionally, two nursing academic/practitioners who worked closely with the SNs and the LLs acted as the local champions. The impacts and benefits of the GSPeP can be discussed in terms of its use in various aspects of the SNs'journey as a teaching, learning, assessment for and of learning tool in collaboration with diverse stakeholders who engage with the eportfolio for student growth and development (Ritzhaupt, et al. 2008) as shown in Figure 1.

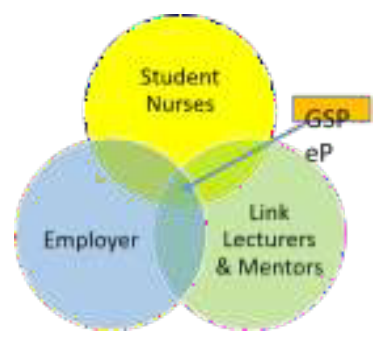

Figure 1. GSPeP-stakeholder interaction model..

The literature has numerous research and case studies offering advice for successful implementations of eportfoliso including recommendations for diverse role holders. For example, according to Barrett (2007), the teacher's role is critical to success; high- performing teachers (as judged by student engagement) effectively used reflection, metacognition and other learning strategies to provide constructive feedback. In the context of GSPeP initiative, Nurse Mentors guide, monitor and assess SNs' learning and development in the practice area while the LLs are responsible for monitoring the continuous learning and development of their link students along a series of practice placements throughout the programme. Table 2 summarises the roles and responsibilities of the SNs, the Mentors and the LLs.

In addition to the scheduled GSPeP online training sessions designed and delivered by the PM on Zoom, she also prepared an eBook Survival Guide to cater for the needs of independent and autonomous learners. The two local champions were also key to communicating with the PM re need to respond to technical as well as non technical issues including privacy of content when GSPeP is published. 
Table 2. Roles and Responsibilities.

\begin{tabular}{ll}
\hline Students & Educators \\
\hline OWN the eportfolio development & Clarify purpose of creating and developing Lifelong Learning \\
process & Nursing eportfolio; if summatively assessed, clarify how \\
Create a Folder of Evidence (FoE) in & Highlight role of eportfolio in the curriculum \\
Google Drive & Create a sense of personal ownership over one's \\
Create files/folders in FoE to organise, & achievements: ownership engenders feelings of pride, \\
curate evidence/artefacts for the & responsibility, dedication (Paris and Ayres 1994:10) \\
purpose of the eportfolio & Make the eportfolio more Conversation than Presentation (or \\
Upload appropriately labelled & Checklist) as the former Transforms! \\
evidence/ artefacts to demonstrate & Assist students create, recognise strengths and weaknesses in \\
achievement of competencies & evidence/artefacts collected \\
Reflect on learning (What? So what? & $\begin{array}{l}\text { Establish timelines for enabling eportfolio engagement } \\
\text { Now what?) }\end{array}$ \\
Share FoE with selected audiences & $\begin{array}{l}\text { Facilitate peer collaboration and feedback on artefacts, } \\
\text { reflections most probably across sites }\end{array}$ \\
Seek feedback from Link Lecturers, & Monitor engagement emphasising the process of eportfolio \\
Mentors, peers & development as a learning journey \\
Engage with peer assessment & Model effective use by sharing own eportfolio \\
& \\
\hline
\end{tabular}

\subsection{Implementing and Supporting}

Another crucial factor for successfully implementing GSPeP is ensuring all end users feel supported and confident in using it. Appropriate training and support for students as well as for the LLs was scheduled and delivered in a timely manner as shown in Table 1.

"When and How to access Link Students' GSPeP" was an additional resource created for the LLs to provide feedback to students' work effectively and efficiently. This consolidated the schedule for the SNs (Table 3). 
Table 3 Timelines for SNs.

\begin{tabular}{lll}
\hline File in FoE & How to tag/label your file/evidence & date to be available in FoE \\
\hline Policies and Guidelines & As available & $\begin{array}{l}\text { during each placement } \\
\text { entity }\end{array}$ \\
Placement Planners & Clinical Placement Planner - Y1 & 11.03 .2020 \\
Student Contracts & Student Contract - Y1 & 05.02 .2020 \\
SWOT Analysis & SWOT analysis - Y1 & 26.02 .2020 \\
Learning Contracts & LC - Y1 & 18.03 .2020 \\
Clinical Placement & Domain 1 - Y1 Domain 2 - Y1 Domain 3 - Y1 \\
$\begin{array}{l}\text { Competencies } \\
\text { Technical Skills Records }\end{array}$ & TSR - Y1 TSR - Y2 TSR - Y3 & work in progress \\
Placement hours & Placement hours Y1 & \\
Link Lecturer and Mentor & LLandMentorFeedback - Y1 & \\
$\begin{array}{l}\text { Feedback } \\
\text { Clinical Placements - }\end{array}$ & Student Feedback- Y1 & \\
$\begin{array}{l}\text { Student Feedback } \\
\text { Records of Evidence }\end{array}$ & Records of Evidence - Y1 & \\
$\begin{array}{l}\text { Placement Documents } \\
\text { Extracurricular Activities }\end{array}$ & Placement Documents - Y1 & \\
\hline
\end{tabular}

Tablel also illustrates a thoughtful plan of how the project leaders pursued a systematic, comprehensive plan for evaluating, gathering, analysing and presenting evidence of the ways the GSPeP shapes student learning resulting in a Project Phase 1 2019-2020 Report which will form the basis of Phase 2 2020-21.

\section{Conclusion and Next Steps: Scaling and Sustaining}

In summary, GSPeP is an example of e-learning practice that evidently addresses the Department of Nursing's current educational needs and "accommodates continuous adaptation to change, without depleting its resource base or receding in effectiveness" (Stepanyan, et al. 2013,p. 95). GSPeP is therefore, a sustainable development defined as "development that meets the needs of the present without compromising the ability of future generations to meet their own needs" (World Commission on Environment and

Development, 1987, p. 43). Future initiatives can be built upon this firm foundation for the sustainability of nurse education in practice that focuses on the implementation of sustainable forms of successful practice through educational development, leadership, and innovation. The Portfolios \& Open Badges Maturity Matrix (Europortfolio, 2014) could be the tool not only for reflection but also for facilitating dialogue with practitioners, leaders in education and decision makers. 


\subsection{From Departmental to Institutional}

In order that the GSPeP implementation and further developments are sustainable, the project team are taking steps to work at the institution level to build relationships and connect their work to institutional plans and systems.

\subsection{Engagement with the wider community}

The project team plan to share good practice within the UM and further afield through publications and conferences.

\subsection{Periodic multifocal evaluation of the GSPeP}

Use the Portfolios \& Open Badges Maturity Matrix (Europortfolio, 2014) for reflection and transformation.

\section{References}

Barrett, H. C. (2007). Researching electronic portfolios and learner engagement: The REFLECT Initiative. Journal of Adolescent \& Adult Literacy, 50(6), 436-449.

Buzzetto-More, N. (2006). The e-Learning and business education paradigm: Enhancing education, assessment, and accountability. Proceedings of the Maryland Business Education Association Conference. Ocean City, MD.

Europortfolio (2014) Eportfolios \& Open badges maturity matrix. Retrieved from http://bit.ly/mmpdf.

Jafari, A. (2004). The sticky e-portfolio system: Tackling challenges and identifying attributes. Educause Review, 39(4), 38-49.

JISC. (2012). The e-portfolio implementation toolkit. Retrieved https:/epip.pbworks.com/w/page/28670505/The\%20eportfolio\%20implementation\%20toolkit.

Paris, S. \& Ayres, L. (1994). Becoming Reflective Students and Teachers. American Psychological Association.

Ritzhaupt, A., Singh, O., Seyferth, T. \& Dedrick, R. (2008). Development of the Electronic Portfolio Student Perspective Instrument: An ePortfolio Integration Initiative. Journal of Computing in Higher Education, 19 (2), 47-71.

Stepanyan, K., Littlejohn, A. \& Margaryan, A. (2013) Sustainable e-Learning: Toward a Coherent Body of Knowledge. Journal of Educational Technology and Society, 16, 91102.

World Commission on Environment and Development (1987). Our Common Future, Oxford University Press: Oxford, UK Oxford 